\title{
Metastatic Non-Functioning Well Differentiated Neuroendocrine Neoplasm
}

National Cancer Institute

\section{Source}

National Cancer Institute. Metastatic Non-Functioning Well Differentiated

Neuroendocrine Neoplasm. NCI Thesaurus. Code C140329.

A non-functioning well differentiated neuroendocrine neoplasm that has spread from the original site of growth to another anatomic site. 